\title{
Flexor Carpi Ulnaris
}

National Cancer Institute

\section{Source}

National Cancer Institute. Flexor Carpi Ulnaris. NCI Thesaurus. Code C53156.

A muscle in the forearm running from the humeral and ulnar heads to the ulnar side of the wrist that flexes and abducts the hand toward the ulna. 